\title{
Bone marrow necrosis as clinical presentation of plasmablastic lymphoma in an AI DS patient: First case reported and literature review
}

\author{
Marcelo Corti $^{1}$, I sabel Soto ${ }^{1}$, María F. Villafañe ${ }^{1}$, Gonzalo Minué ${ }^{2}$, Ana Campitelli ${ }^{3}$, Marina \\ Narbaitz $^{4}$ \\ 1.Division of HIV/AIDS Disease, F. J. Muñiz Hospital, Buenos Aires, Argentina. 2. Hematology Unit, F. J. Muñiz Hospital, \\ Buenos Aires, Argentina. 3. Histopathology Laboratory, F. J. Muñiz Hospital, Buenos Aires, Argentina. 4. Histopathology \\ Laboratory, National Academy of Medicine, Buenos Aires, Argentina
}

Correspondence: Marcelo Corti. Address: Division of HIV/AIDS, Infectious Diseases F. J. Muñiz Hospital, Puán $3812^{\circ}$ Postal code C 1406 CQG, Buenos Aires, Argentina. Email: marcelocorti@fibertel.com.ar

Received: May 23, 2013

Accepted: July 11, 2013

Online Published: August 7, 2013

DOI : $10.5430 /$ jhm.v3n1p57

URL: http://dx.doi.org/10.5430/jhm.v3n1p57

\begin{abstract}
Patients with HIV/AIDS disease are at high risk of developing non-Hodgkin lymphoma (NHL) which is included as an AIDS-defining illness. Plasmablastic lymphoma (PBL) most frequently presents in the oral cavity and generally in patients with HIV infection. Extra-oral PBL is a rare tumor but with a similar capability to local invasion and rapid dissemination to extra-oral sites. Bone marrow necrosis (BMN) associated with high grade B cell lymphoproliferative disease is a rare condition that should be suspected in HIV-infected patients with unexplained fever and cytopenias. Here we describe the first case of BMN caused by a high grade NHL diagnosis as PBL in an AIDS patient.
\end{abstract}

\section{Key words}

Bone Marrow Necrosis, Plasmablastic Lymphoma, HIV, AIDS, Epstein-Barr virus

\section{I ntroduction}

Bone marrow necrosis (BMN) is a rare and generally fatal complication which can be seen in the course of a wide variety of different diseases, especially in hematological malignancies ${ }^{[1]}$. BMN has been reported associated with infectious diseases, leukemia, Hodgkin's lymphoma (HL), non-Hodgkin's lymphomas (NHL) and metastatic carcinomas. Other conditions associated with this severe complication include antiphospholipid syndrome, chemotherapy and during treatment with retinoic acid, fludarabine, interferon $\alpha$ and granulocyte-colony-stimulating-factor ${ }^{[2]}$. The frequency of BMN in bone marrow biopsies is less than $1 \%{ }^{[1,2]}$.

We present an AIDS patient who developed a BMN associated with fever and pancytopenia as a clinical presentation of PBL. 


\section{Case presentation}

A 42 year-old homosexual male was admitted to the AIDS-related infectious diseases department of our hospital with persistent fever, diffuse mioarthralgias (especially lower back pain), weight loss, dyspnea, cough and night sweats. He had history of intravenous drug use and human immunodeficiency virus (HIV) and hepatitis C virus (HCV) co-infection since 2002, without antiretroviral therapy due to his own decision. He had lost approximately $15 \mathrm{~kg}$ weight during the previous 3 months. Physical examination revealed an ill-looking patient with fever $\left(38.5-39^{\circ} \mathrm{C}\right)$, mild to moderate dyspnea, II-III functional class according to the New York Heart Association (NYHA), pallor and hepatosplenomegaly. Also, he presented numerous lesions compatible with the clinical diagnosis of Kaposi's sarcoma, located in the skin and the oral mucosa. International Prognostic Index (IPI) score was high. Relevant laboratory findings were pancytopenia with leucocytes count $1.7 \times 10^{3} / \mu \mathrm{L}$ with neutrophils $53 \%$, eosinophils $1 \%$, lymphocytes $24 \%$ and monocytes $22 \%$, red blood count $1.9 \times 10^{6} / \mu \mathrm{L}$ and platelets $79 \times 10^{3} / \mu \mathrm{L}$. The erythrocyte sedimentation rate was more than $140 \mathrm{~mm} / 1 \mathrm{st}$ hour, hemoglobin $5.4 \mathrm{~g} / \mathrm{L}$, alkaline phosphatase (ALP) level $570 \mathrm{U} / \mathrm{L}$ (normal range up to $270 \mathrm{U} / \mathrm{L}$ ) and lactate dehydrogenase (LDH) level $1620 \mathrm{U} / \mathrm{L}$ (normal range up to $460 \mathrm{U} / \mathrm{L}$ ). His liver and renal function tests were normal; the CD4 T-cell count was 3 cells $/ \mu \mathrm{L}$. A chest X-ray showed unspecific bilateral infiltrates; multiple sputum and urine cultures were negative. An echocardiography showed no pathological alterations and the abdominal ultrasound revealed homogeneous hepatomegaly and splenomegaly. Fiberoptic bronchoscopy was performed; microbiological cultures of bronchoalveolar secretions for micobacteria and fungus were negative. Histopathological examination of biopsy skin obtained from cutaneous lesions confirmed the suspected diagnosis of Kaposi's sarcoma. A first bone marrow biopsy was taken and showed extensive areas of BMN but was undetermined for diagnosis (see Figure 1 and 2). A second bone marrow aspirate and biopsy was necessary; histopathological examination revealed extensive areas of necrosis and an infiltrate composed of a diffuse proliferation of large immunoblastic cells with the typical morphological appearances of a high-grade NHL. Numerous cells had a plasmablastic appearance. Immunostaining with monoclonal antibodies showed that the atypical cells were negative for standard B-cell markers CD3, CD20 and CD34 and the majority of neoplastic cells express MUM-1, CD138, and partially for CD45 and CD30 (see Figure 3). All antibodies were obtained from DAKO (Glostrup, Denmark). Bcl-6 was negative and the Ki-67 (proliferative) index was high ( $>85 \%$ of the tumor cells). Definitive histopathological diagnosis was BMN due to high grade plasmablastic NHL. Epstein-Barr virus (EBV)-encoded mRNAs (EBERs) were detected in tumor cells by in situ hybridization (ISH) in $40 \%$ of the neoplastic cells (see Figure 4). Polymerase chain reaction was negative to detect HHV-8 genome in bone marrow biopsy smears. His clinical condition deteriorated progressively and only supportive treatment was started. He died 4 weeks after admission.

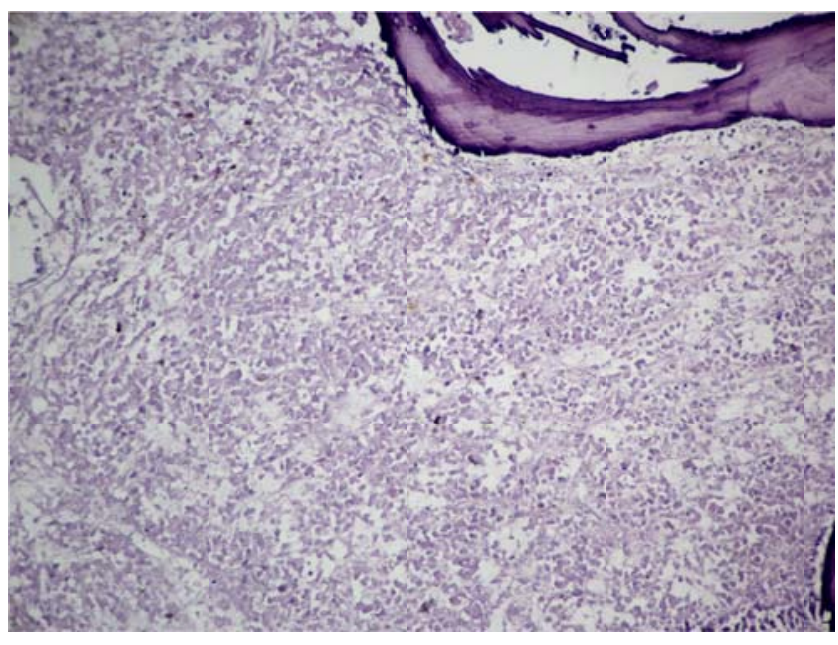

Figure 1. H\&E: bone marrow biopsy showed extensive areas of coagulation necrosis $(40 \mathrm{X})$

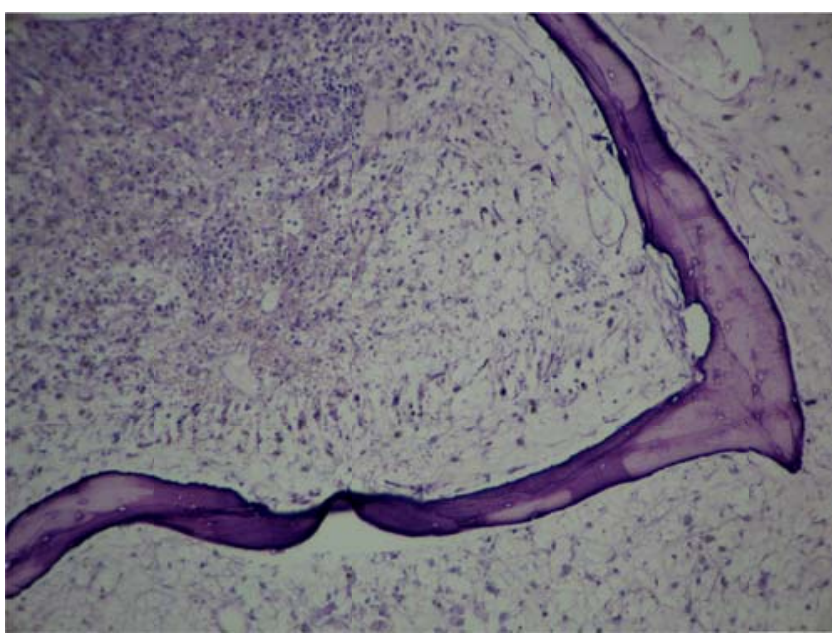

Figure 2. Hematoxylin and eosin stain of extensive bone marrow necrosis $(10 \mathrm{X})$ 


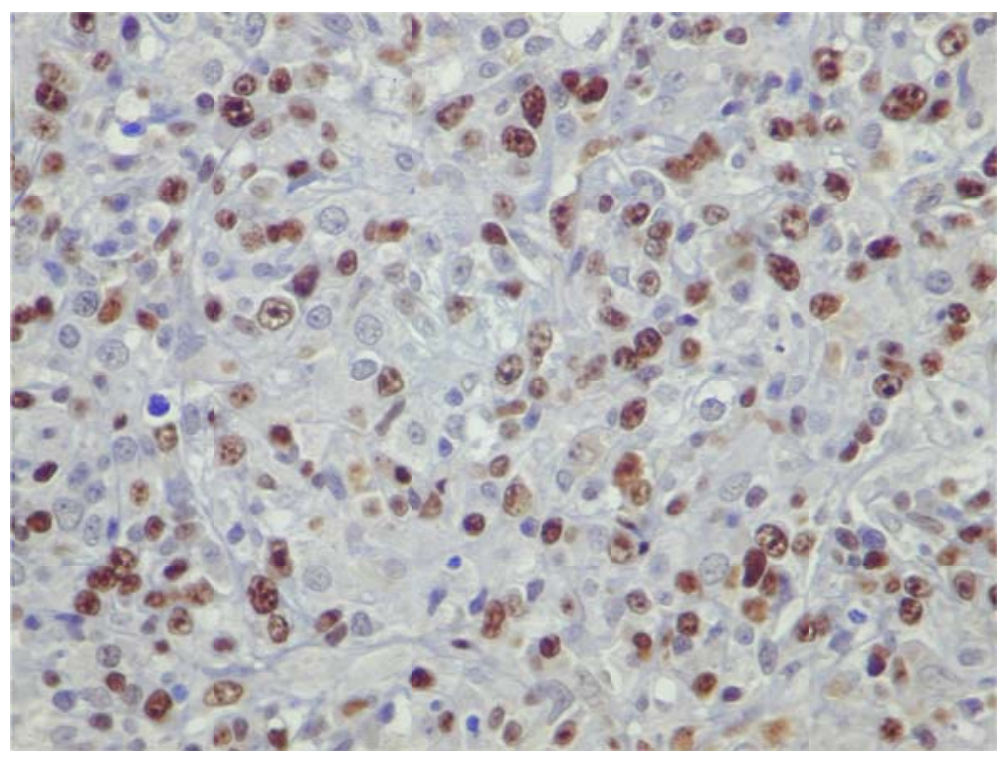

Figure 3. Immunohistochemical of PBL: MUM-1 expression in the neoplasic cells (40 X)

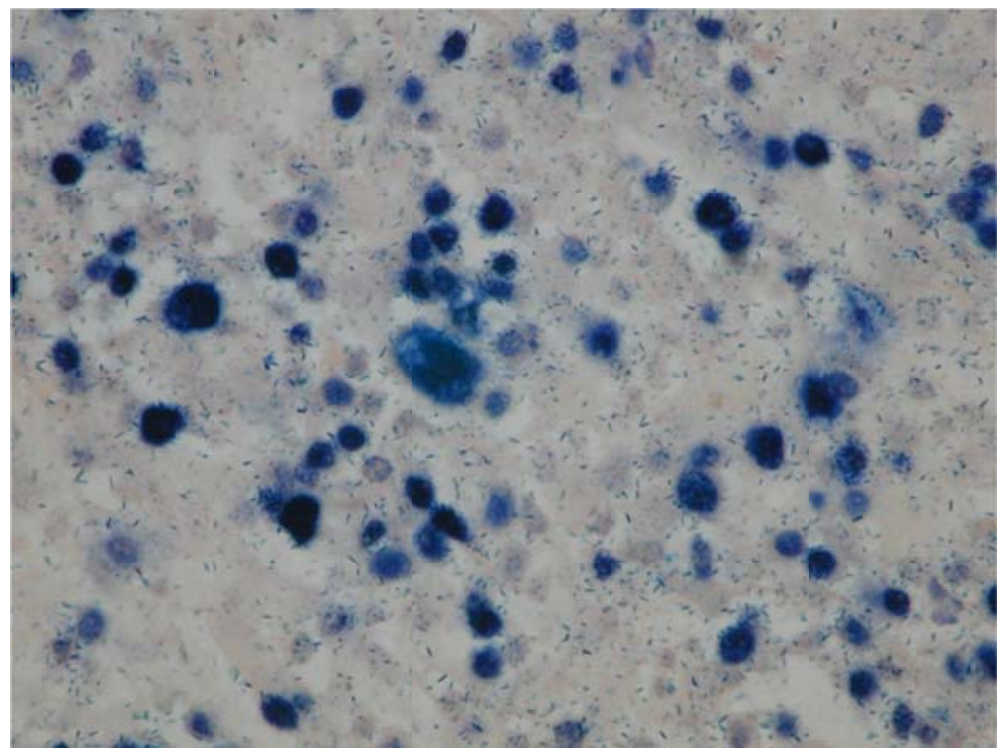

Figure 4. EBV-encoded RNA (EBERs) was expressed in the atypical cells (40 X)

\section{Discussion}

BMN is defined pathologically as a necrosis of myeloid tissue and medullar stroma in large areas of the bone marrow with preservation of the bone. According to the extension and stromal infiltration, BMN is classified as minor (grade I) BMN with less than $20 \%$ of necrosis in the biopsy, intermediate (grade II) involving $20 \%-50 \%$ of the bone marrow and severe (grade III) affecting more than $50 \%$ of the bone marrow ${ }^{[3]}$. BMN is an uncommon complication and the literature review estimated less than 300 cases have been reported ${ }^{[4]}$. Two large studies evaluated the frequency of BMN in bone marrow trephine biopsies. Eishi et al. ${ }^{[1]}$ in a descriptive study evaluated a total of 800 bone marrow biopsies with only 8 cases of $\operatorname{BMN}(0.94 \%)$ found. In another study, Bashawri et al. ${ }^{[2]}$ analyzed a total of 1065 bone marrow biopsies, five of them were diagnosed as a variable grade of BMN accounting a relative frequency of a $0.47 \%$. 
Ninety percent of the BMN cases are associated with malignancy, and hemopoietic malignancies are the cause of BMN in $60 \%$ of the patients ${ }^{[5,6]}$. Among them, acute leukemia has been found to be the most common underlying disease ${ }^{[7-9]}$. Other malignant causes of BMN are lymphomas, chronic myeloproliferative disorders and solid tumors ${ }^{[4]}$. For these reasons, malignancy should always be excluded in a patient with BMN without a clear etiology ${ }^{[10]}$. Paydas et al ${ }^{[3]}$ detected 23 cases of patients with BMN among 1083 bone marrow biopsies with a prevalence of $2.2 \%$; $80 \%$ had underlying malignant diseases and only four $(20 \%)$ had nonmalignant diseases. Among the malignant cases, the majority of patients had haematological malignancies. As of the nonmalignant cases, two had tuberculosis infection, one had anti-phospholipid syndrome and one had a history of drug abuser.

Patients with diagnosis of BMN and non malignant etiology are interesting. It is known that tuberculosis has variable haematological findings and BMN is a rare complication ${ }^{[11]}$. However, some reviews suggest that tuberculosis may be another cause of BMN; in patients with BMN, diagnosis of tuberculosis must be considered, especially, in those patients with peripheral cytopenias ${ }^{[12]}$.

Clinically this complication is characterized by fever, pancytopenia and bone pain which are seen in $80 \%$ of the cases, and it may be disseminated or localized as lower back pain, as we could see in our patient.

The cause of fever in BMN may be associated with tissue necrosis, as seen in other necrosis, or it may be associated with accompanying neutropenia. The exact cause of fever in neutropenic cases cannot be completely described. Fatigue associated with anemia and bleeding due to thrombocytopenia is seen in the majority of the cases ${ }^{[4]}$. Elevated LDH and ALP are the most common laboratory findings associated with tissue BMN, as we could find in our patient. Generally, in patients with lymphomas, BMN is the end result of the massive infiltration by atypical lymphoid cells, chemotherapy or arterial occlusion $^{[10,13,14]}$.

PBL is a distinct disease entity of the diffuse large B cell lymphomas which occurs in HIV-seropositive patients. Typically, PBL occurs in the oral cavity. It is associated with latent EBV infection in $70 \%$ of the cases and accounts for $2.6 \%$ of NHL in this population. This subtype of NHL is characterized by their rapid progression and poor outcome. There are a few reports in the medical literature of cases of extra-oral compromise as we could see in our patient. The immunophenotype of this lymphoid neoplasm is consistent with the plasma cell-markers associated antigens VSC38c and CD 138 AS CD28 ABD CD $45^{[15]}$.

In AIDS patients, viral infection, especially EBV infection has been strongly associated with the pathogenesis of $\mathrm{PBL}^{[16,17]}$. HHV-8 is other oncogenic virus that has also been reported in association with PBL in AIDS patients ${ }^{[18,19]}$.

Also, HCV should have a role in patients co-infected with HIV. Durberg et al. ${ }^{[20]}$ described that patients infected with HCV have a high risk to develop NHL than in the general population. The patent that we described was HCV positive probable related to the source of HIV infection.

Frequently, bone marrow aspiration is non-diagnostic due to insufficient and or undescribed material in the majority of the cases and multiple aspirations and biopsies may be generally necessary, as in this case. Thus bone marrow trephine biopsy is performed to reveal the diagnosis of $\mathrm{BMN}^{[21]}$.

Bone marrow necrosis is frequently documented at postmortem examination ${ }^{[14]}$. When specifically looked for in retrospective reviews of consecutive bone marrow biopsies, some degree of marrow necrosis varying from mild to severe is seen in approximately one third of samples ${ }^{[22]}$. Severe degrees of bone marrow necrosis are almost always associated with life-threatening clinical conditions, leading to the general impression that when the degree of necrosis is severe, the clinical outcome is much worse ${ }^{[21,22]}$. 
BMN is an infrequent antemortem diagnosis and is associated with a poor prognosis, generally related with haematological malignancies ${ }^{[23]}$.

The Medline, Embase and Cochrane databases were searched to identify other cases of BMN due to plasmablastic lymphoma in AIDS patients. Terms used in the search were: bone marrow necrosis, plasmablastic lymphoma, AIDS and HIV. We didn't find any manuscript about this subject.

In conclusion, BMN is a different clinicopathological entity that should be included in the differential diagnosis of AIDS patients with fever and pancytopenia; hematopoietic malignancies are the most common causes of BMN. Early bone marrow biopsy and histopathological examination should be necessary to improve the poor prognosis of this kind of patients.

\section{References}

[1] Eishi A, Ilkhanizade B, Rahimi E. Bone Marrow Necrosis: Frequency and Clinicopathological Findings in Marrow Biopsies. Iran J Pathol. 2009; 4:38-43.

[2] Bashawri L, Satti MB. Bone marrow necrosis: report of five cases and review of the literature. Ann Saudi Med. 2000; $20: 78-82$. PMid:17322755

[3] Paydas S, Ergin M, Baslamisli F, Yavuz S, Zorludemir S, Sahin B, et al. Bone marrow necrosis: clinicopathologic analysis of 20 cases and review of the literature. Am J Hematol. 2002; 70:300-305. PMid:12210811 http://dx.doi.org/10.1002/ajh.10114

[4] Janssens AM, Offner FC, Van Hove WZ. Bone marrow necrosis. Cancer. 2000; 88: 1769-1780. http://dx.doi.org/10.1002/(SICI)1097-0142(20000415)88:8<1769::AID-CNCR3>3.0.CO;2-H

[5] Kiraly JF, Wheby MS. Bone marrow necrosis. Am J Med. 1976; 60: 361-368. http://dx.doi.org/10.1016/0002-9343(76)90752-X

[6] Invernizzi R, D’Alessio A, Iannone AM, Pecci A, Bernuzzi S, Castello. Bone marrow necrosis in acute lymphoblastic leukemia. Haematologica. 1995; 80:572-573. PMid:8647526

[7] Shibata K, Shimamoto Y, Watanabe M, Kikuchi M, Yamaguchi M. Two cases of acute lymphocytic leukemia associated with bone marrow necrosis: a brief review of recent literature. Eur J Haematol. 1994; 52:115-116. PMid:8119381 http://dx.doi.org/10.1111/j.1600-0609.1994.tb01296.x

[8] Moraleda JM, Gonzalez R, Alegre A, Anta JP, San Miguel JF. Bone marrow necrosis and treatment with interferon. J Clin Pathol. 1986; 39:1045. PMid:3463567 PMCid:PMC500212 http://dx.doi.org/10.1136/jcp.39.9.1045

[9] Niebrugge DJ, Benjamin DR. Bone marrow necrosis preceding acute lymphoblastic leukemia in childhood. Cancer. 1983; 52:162-164. http://dx.doi.org/10.1002/1097-0142(19831201)52:11<2162::AID-CNCR2820521131>3.0.CO;2-A

[10] Granot H, Polliack A, Matzner Y. Bone marrow necrosis as the only manifestation of disseminated carcinomatosis. Acta Haematol. 1980; 64:232-235. PMid:6781206 http://dx.doi.org/10.1159/000207264

[11] Katzen H, Spagnolo SV. Bone marrow necrosis from miliary tuberculosis. J Am Med Assoc. 1980; 244:2438-2439. PMid:7431572 http://dx.doi.org/10.1001/jama.1980.03310210040024

[12] Markovic SN, Phyliky RL, Li CY. Pancytopenia due to bone marrow necrosis in acute myelogenous leukemia: role of reactive CD8 cells. Am J Hematol. 1998; 59:74. http://dx.doi.org/10.1002/(SICI)1096-8652(199809)59:1<74::AID-AJH14>3.0.CO;2-1

[13] Granot H, Polliack A, Matzner Y. Bone marrow necrosis as the only manifestation of disseminated carcinomatosis. Acta Hematol. 1980; 64:232-235. http://dx.doi.org/10.1159/000207264

[14] Lackner H, Strenger V, Sovinz P, et al. Bone marrow necrosis in a girl with Hodgkin's disease. Support Care Cancer. 2012; 20: 2231-4. http://dx.doi.org/10.1007/s00520-012-1502-z

[15] Hansra D, Montague N, Stefanovic A, et al. Oral and extraoral plasmablastic lymphoma: similarities and differences in clinicopathologic characteristics. J Clini Pathology. 2010; 134: 710-719. PMid:20959653

http://dx.doi.org/10.1309/AJCPJH6KEUSECQLU

[16] Delecluse HJ, Anagnostopoulos I, Dallenbach F, Hummel M, Marafioti T, Schneider U, et al. Plasmablastic lymphoma of the oral cavity: a new entity associated with the human immunodeficiency virus infection. Blood. 1997; 89: 1413-1420. PMid:9028965

[17] Flaitz CM, Nichols CM, Walling DM, Hicks MJ. Plasmablastic lymphoma: an HIV-associated entity with primary oral manifestations. Oral Oncol. 2002; 38: 96-102. http://dx.doi.org/10.1016/S1368-8375(01)00018-5

[18] Corti M, Villafañe MF, Solari R, De Carolis L, Cangelosi D, Santoro J SchtirbuR, Lewi D, Bistmans A, Narbaitz M, Baré P. Non-Hodgkin lymphomas of the oral cavity in AIDS patients in a reference hospital of Infectious Diseases in Argentina: Report of 
eleven cases and review of the literature. J Gastrointest Canc. 2011; 42:143-148. PMid:20563896 http://dx.doi.org/10.1007/s12029-010-9173-9

[19] Corti M, Villafañe MF, Bistmans A, Campitelli A, Narbaitz M, Baré P. Oral cavity and extra-oral plasmablastic lymphomas in AIDS patients. Report of 5 cases and review of the literature. Int J STD \& AIDS. 2011; 22: 759-763. PMid:22174064 http://dx.doi.org/10.1258/ijsa.2011.011235

[20] Durberg AS, Nordstrom M, Torner A, Reichard O, Strauss R, Janzon R, et al. Non-Hodgkin's lymphoma and other nonhepatic malignancies in Swedish patients with hepatitis C virus infection. Hepatology. 2005; 4:652-659. PMid:15723449 http://dx.doi.org/10.1002/hep.20608

[21] Maisel D, Lim JY, Pollock WJ, Yatani R, Liu PI: Bone marrow necrosis: An entity often overlooked. Ann Clin Lab Sci. 1988; 18:109-115. PMid:3382156

[22] Ranaghan L, Morris TCM, Desai ZR, Markey GM. Bone Marrow Necrosis. Am J Hematol. 1994; 47:225-228. PMid:7942788 http://dx.doi.org/10.1002/ajh.2830470314

[23] Bhasin TS, Sharma S, Chandey M, Bhatia PK, Mannan R. A case of bone marrow necrosis of an idiophatic aetiology: the report of a rare entity with review of the literature. J Clin Diagn Res. 2013; 7:525-528. http://dx.doi.org/10.7860/JCDR/2013/4919.2812 